J. Dairy Sci. 92:3292-3298

doi:10.3168/jds.2008-1772

(c) American Dairy Science Association, 2009.

\title{
Effect of dietary dry matter concentration on the sorting behavior of lactating dairy cows fed a total mixed ration
}

\author{
E. K. Miller-Cushon and T. J. DeVries ${ }^{1}$ \\ Department of Animal and Poultry Science, University of Guelph, Kemptville Campus, Kemptville, Ontario, K0G 1J0, Canada
}

\section{ABSTRACT}

The objective of this study was to determine whether addition of water to a high-moisture total mixed ration reduces feed sorting by dairy cattle. Twelve lactating Holstein cows, individually fed once per day, were tested on 2 diets in a crossover design with 21-d periods. Diets had the same dietary composition and differed only in dry matter content, which was reduced by the addition of water. Treatment diets were 1) dry (57.6\% DM) and 2$)$ wet $(47.9 \% \mathrm{DM})$. Dry matter intake (DMI) and milk production were monitored for each animal for the last $7 \mathrm{~d}$ of both treatment periods. For the final 3 $\mathrm{d}$ of each period, milk samples were taken for composition analysis and fresh feed and orts were sampled for particle size analysis. The particle size separator had 3 screens $(19,8$, and $1.18 \mathrm{~mm})$ and a bottom pan, resulting in 4 fractions (long, medium, short, fine). Sorting was calculated as the actual intake of each particle size fraction expressed as a percentage of the predicted intake of that fraction. Contrary to the hypothesis, cows sorted the wet diet more extensively than the dry diet. Sorting of the dry diet was limited to a tendency to refuse short particles, whereas the wet diet was sorted against long particles and for short and fine particles. Water addition reduced DMI, neutral detergent fiber intake, and starch intake of cows on the wet diet. Increased sorting on the wet diet resulted in a tendency for decreased concentration of dietary neutral detergent fiber consumed and also resulted in increased starch concentration of the diet consumed. Milk production and components were unaffected by treatment. Our results suggest that water addition to high-moisture total mixed rations, containing primarily haylage and silage forage sources, may not be an effective method to reduce sorting. Furthermore, water addition may negatively affect DMI and encourage sorting, resulting in the consumption of a ration with different nutrient composition than intended.

Key words: sorting, dry matter content, dairy cow

Received October 1, 2008.

Accepted February 25, 2009.

${ }^{1}$ Corresponding author: tdevries@kemptvillec.uoguelph.ca

\section{INTRODUCTION}

Total mixed rations are designed as a homogeneous mixture to help minimize the selective consumption of individual feed components by dairy cattle (Coppock et al., 1981). Despite providing feed as a TMR, researchers have shown that extensive diet selection (sorting) of a TMR occurs. In previous research, DeVries et al. (2005) found that the NDF content of the TMR in the feed bunk increased throughout the day, indicating cows were selecting against greater fiber components of the diet. Similarly, other researchers have shown that most cows tend to select for smaller concentrate particles instead of long forage particles (Leonardi and Armentano, 2003). In such cases, the diet actually consumed by cows is greater in fermentable carbohydrates than intended and lesser in effective fiber, thereby increasing the risk of subacute ruminal acidosis (DeVries et al., 2008).

One proposed method of reducing feed sorting is the addition of water to dry TMR (Shaver, 2002). It is commonly believed that addition of water to dry TMR will bind particles together and make it harder for dairy cattle to sort out fine particles. This hypothesis was tested in an experiment by Leonardi et al. (2005), who showed a reduction in the extent of feed sorting against long particles and for short particles when water was added to a dry TMR (80\% DM). There was also a trend for cows to increase NDF intake with the wetter ration. The greater intake of long, fibrous particles on the wetter ration likely contributed to the trend for greater milk fat percentage (3.41 vs. 3.31\%; Leonardi et al., 2005). These authors concluded that the addition of water to dry dairy TMR is a cost-effective management practice that dairy producers may implement to reduce sorting. A major caveat in interpretation and implementation of the results of this study is the fact that the ration tested was much drier than that typically utilized for high-production dairy herds (40 to $60 \%$ DM; Eastridge, 2006). Even the "wet" ration $(64 \% \mathrm{DM})$ in the aforementioned study would be considered somewhat dry compared with those TMR that utilize haylage and silage as the primary forage sources. The objective, therefore, of this study was to further 
examine the effects of dietary DM concentration on the feed sorting behavior of lactating dairy cows fed a high-moisture TMR. The hypothesis for the study was that the addition of water to a high-moisture TMR will decrease feed sorting, and thus decrease the refusal of NDF, and will ultimately increase milk fat percentage and yield.

\section{MATERIALS AND METHODS}

\section{Animals and Housing}

Twelve lactating Holstein cows, 6 primiparous and 6 multiparous (parity $=2.8 \pm 1.2$; mean $\pm \mathrm{SD}$ ), were used in the study. Animals were $139.3 \pm 53.3$ DIM at the beginning of the data collection period. Cows were housed together in a tie-stall barn located at the University of Guelph, Kemptville Campus Dairy Education and Research Centre (Kemptville, ON, Canada). Cows were managed according to the guidelines set by the Canadian Council on Animal Care (1993).

Each cow was individually housed in a tie stall with ad libitum access to water (via an individual water bowl) and feed (via a feed bunk containing dividers separating adjacent cows' feed). Cows were milked in their stalls twice daily at 0500 and $1600 \mathrm{~h}$. Cows were fed a TMR once daily at $1000 \mathrm{~h}$. Orts from each feeding were removed from the feed bunk before the subsequent feed delivery. Cows were given a 2 -h exercise period (0800 to $1000 \mathrm{~h}$ ) each day in an outside dry lot pen. The experiment was conducted between May 17 and June 27. The average environmental temperature during the data collection periods was $17.9 \pm 2.5^{\circ} \mathrm{C}$.

\section{Experimental Design and Diets}

The number of animals required per treatment was determined through power analysis (Morris, 1999) for the primary response variables, including DMI, feed sorting, and milk production and composition. Estimates of variation for these variables were based on previously reported values (Leonardi et al., 2005; DeVries et al., 2007; Bhandari et al., 2008). Cows were divided into 2 groups of 6 , which were balanced according to DIM, milk production, and average parity (1.9 \pm 1.2 ). These groups were created by blocking cows into groups of 2 cows (similar in parity, DIM, and milk production), and then randomly assigning the cows in these blocks to 1 of the 2 experimental groups.

Cows were then exposed to 2 treatments (Table 1 ) in a crossover design with 21-d periods. The treatments were: 1) control diet (designated dry), and 2) control diet with water (designated wet). The control diet was formulated to meet nutrient requirements of high- producing lactating dairy cows (NRC, 2001). Dietary ingredients were mixed for approximately $10 \mathrm{~min}$ in a TMR mixer wagon (Reel-Auggie model 3250, Kuhn Knight, Inc., Brodhead, WI). After mixing, the ration was transferred to a feed cart (WIC MDR-55, Ideal Machinery Inc., Wickham, QC, Canada) from which cows were fed. No mixing of the ration occurred while the ration was being fed. For the wet diet, water was added into the mixer during diet preparation. The amount of water added constituted $20 \%$ of the diet (DM basis) and was the amount of water necessary to decrease the dietary DM content from approximately $60 \%$ to approximately $50 \%$. The amount of feed offered to each cow was adjusted daily to ensure approximately $15 \%$ orts. Cows were kept on their respective treatments for $21 \mathrm{~d}$ and then switched to the other treatment and fed for an additional $21 \mathrm{~d}$.

\section{Feed Sampling and Analysis}

For determination of DM and nutrient content, representative samples of treatment TMR and individual orts of each cow were taken during the last $7 \mathrm{~d}$ of each treatment period. Duplicate samples of treatment TMR and individual orts of each cow were taken for particle size separation during the last $3 \mathrm{~d}$ of each treatment period. Additionally, on the third last day of each treatment period, duplicate samples of the dietary components were taken to estimate particle size analysis and chemical analysis. All samples were immediately frozen at $-20^{\circ} \mathrm{C}$ until they were further analyzed.

Samples for particle size separation were separated using the 3-screen (19, 8, and $1.18 \mathrm{~mm})$ Penn State Particle Separator (PSPS; Kononoff et al., 2003). This separated the particles into 4 fractions: long $(>19 \mathrm{~mm})$, medium $(<19,>8 \mathrm{~mm})$, short $(<8,>1.18 \mathrm{~mm})$ and fine $(<1.18 \mathrm{~mm})$ particles. After separation, the DM of each separated fraction was determined by oven drying at $55^{\circ} \mathrm{C}$ for $48 \mathrm{~h}$. The physical effectiveness factor (pef) was determined as the DM proportion of particles retained by the top 2 sieves of the PSPS (Yang and Beauchemin, 2006). The physically effective NDF (peNDF) was calculated by multiplying the NDF content of the feed by the pef.

Samples taken for DM and chemical analysis were oven-dried at $55^{\circ} \mathrm{C}$ for $48 \mathrm{~h}$ and then ground to pass through a 1-mm screen (Brinkmann Mill, Brinkmann Instruments Co., Westbury, NY). These samples, plus the dried TMR particle fractions, were sent to Cumberland Valley Analytical Services Inc. (Maugansville, MD) for analysis of DM $\left(135^{\circ} \mathrm{C}\right.$; AOAC, 2000 ; method 930.15), ash (535 $\mathrm{C}$; AOAC, 2000; method 942.05), ADF (AOAC, 2000; method 973.18), NDF with heat-stable a-amylase and sodium sulfite (Van Soest et al., 1991), 
and $\mathrm{CP}(\mathrm{N} \times 6.25$; AOAC, 2000; method 990.03; Leco FP-528 Nitrogen Analyzer, Leco, St. Joseph, MI).

\section{Milk Production and Components}

Daily milk production for each cow was monitored for the last $7 \mathrm{~d}$ of each experimental period. Milk samples were taken from each animal at each milking for the last $3 \mathrm{~d}$ of each treatment period. These samples were sent to the DHI testing laboratory (Ontario Dairy Herd Improvement Corp., Guelph, Ontario, Canada) for analysis. Milk samples were analyzed for milk protein and fat percentage using a near-infrared analyzer (Foss System 4000, Foss Electric, Hillerød, Denmark). Milk fat and protein yield $(\mathrm{kg} / \mathrm{d})$ were calculated, for the last $3 \mathrm{~d}$ of each treatment period, based on the product of the milk production yield and milk composition at each milking on those days.

\section{Calculations and Statistical Analysis}

Sorting activity for each fraction of the PSPS was calculated as the actual intake of each fraction expressed as a percentage of the predicted intake of that fraction (Leonardi and Armentano, 2003). The predicted intake of an individual fraction was calculated as the product of the DMI of the total diet multiplied by the DM percentage of that fraction in the fed TMR. Values equal to $100 \%$ indicate no sorting, $<100 \%$ indicate selective refusals (sorting against), and $>100 \%$ indicate preferential consumption (sorting for).

Data for the particle size distribution, pef, and peNDF of the diets, DM content of the TMR and orts, as well as the daily intakes, sorting activity, milk yield, and milk composition were summarized for each cow by treatment period. To test whether sorting of the experimental diets occurred, sorting activity for each fraction of the PSPS was summarized by treatment and tested for a difference from 100 using $t$-tests. All data were then analyzed using the Mixed procedure of SAS (SAS Institute, 2003). The final model included the fixed effects of period, order, and treatment, the random effect of cow within order, and the residual error. Interactions of the fixed effects were tested in the initial model and were not significant; therefore, they were dropped from the final analysis. All values reported are least squares means. Significance was declared at $P \leq$ 0.05 , and trends reported if $0.05<P \leq 0.10$.

\section{RESULTS}

Nutrient composition and particle size distribution of treatment diets are reported in Table 1 and Table 2, respectively. The addition of water to the dry diet reduced
Table 1. Ingredient and chemical composition of the treatment diets

\begin{tabular}{lc}
\hline & \multicolumn{2}{c}{ Diet $^{1}$} \\
\cline { 2 - 2 } Composition & Wet \\
\hline Ingredient, \%DM & Dry \\
Corn silage $^{2}$ & 27.04 \\
Alfalfa haylage $^{3}$ & 27.04 \\
High moisture corn $_{\text {Concentrate pellet }}{ }^{5}$ & 28.10 \\
Chemical composition & 17.83 \\
DM, \% & \multicolumn{2}{c}{$47.9 \pm 4.9$} \\
OM, \% of DM & $57.6 \pm 2.6$ \\
CP, \% of DM & $92.1 \pm 0.6$ \\
ADF, \% of DM & $17.4 \pm 0.5$ \\
NDF, \% of DM & $19.1 \pm 0.8$ \\
NFC, \% of DM & $29.6 \pm 0.9$ \\
Starch, \% of DM & $43.3 \pm 1.2$ \\
\hline
\end{tabular}

${ }^{1}$ Dry $=$ control diet without water added; wet $=$ control diet plus $20 \%$ water added (DM basis).

${ }^{2}$ Corn silage had a DM of $46.9 \pm 4.1 \%$ and chemical composition (DM basis) of $7.6 \pm 0.1 \% \mathrm{CP}, 20.2 \pm 0.3 \% \mathrm{ADF}$, and $35.0 \pm 1.1 \%$ NDF. Particle size distribution of corn silage (DM basis) was $4.5 \pm$ $0.8 \%$ long, $70.5 \pm 6.1 \%$ medium, $22.2 \pm 3.1 \%$ short, and $2.8 \pm 2.2 \%$ fine particles. Particle size was determined by a Penn State Particle Separator, which has a 19-mm screen (long), 8-mm screen (medium), 1.18-mm screen (short), and a pan (fine).

${ }^{3}$ Alfalfa haylage had a DM of $53.6 \pm 2.3 \%$ and chemical composition (DM basis) of $20.8 \pm 0.7 \% \mathrm{CP}, 36.3 \pm 2.2 \% \mathrm{ADF}$, and $44.9 \pm 1.6 \%$ NDF. Particle size distribution of alfalfa haylage (DM basis) was 31.0 $\pm 4.2 \%$ long, $36.9 \pm 2.0 \%$ medium, $24.2 \pm 0.3 \%$ short, and $7.8 \pm 2.5 \%$ fine particles.

${ }^{4}$ Supplied by New-Life Mills Ltd. (Inkerman, ON, Canada), containing (on as-is basis): $31.1 \%$ soybean meal, $24.8 \%$ Tri-Pro Gold (Tri-County Protein Corp., Winchester, ON, Canada), $16.9 \%$ corn gluten meal, $11.3 \%$ canola meal, $5.1 \%$ trace mineral/vitamin premix, $4.4 \%$ sodium bicarbonate, $4.4 \%$ ground limestone, $1.9 \%$ cobaltized-iodized salt.

${ }^{5}$ Values were obtained from chemical analysis of TMR samples. $\mathrm{OM}=$ $100-\%$ ash. $\mathrm{NFC}=100-(\% \mathrm{CP}+\% \mathrm{NDF}+\%$ fat $+\%$ ash $)$.

the DM by approximately $10 \%$ to produce the wet diet. The particle size distribution of the TMR was affected by the addition of water, with a decreased amount of $\mathrm{DM}$ retained in the pan $(<1.18 \mathrm{~mm})$. There was no difference in pef and peNDF between diets. The NDF and starch content of the different particle fractions were not different between diets. The NDF content decreased with particle size in both diets, whereas starch content was less for long particles, and greater for the 3 smaller particle fractions. The DM percentage of the different particle fractions of the offered and refused TMR can be seen in Table 3. The DM percentage was less for the wet diet, whereas DM percentage generally increased with decreased particle size across treatments.

Cows sorted against long particles $(>19.0 \mathrm{~mm})$ when fed the wet diet, but did not sort against these on the dry diet (Table 4), resulting in a tendency for a difference between treatments. There was no overall sorting for or against medium particles $(<19.0,>8.0 \mathrm{~mm})$ on either treatment diet. Cows tended to sort against short particles $(<8.0,>1.18 \mathrm{~mm})$ when fed the dry diet, but 
Table 2. Particle size distribution, ${ }^{1} \mathrm{NDF}$, and starch content of the particle fractions, and effective fiber content of the treatment diets

\begin{tabular}{|c|c|c|c|c|}
\hline \multirow[b]{2}{*}{ Item } & \multicolumn{2}{|c|}{$\operatorname{Diet}^{2}$} & \multirow[b]{2}{*}{$\mathrm{SE}$} & \multirow[b]{2}{*}{$P$-value } \\
\hline & Dry & Wet & & \\
\hline \multicolumn{5}{|c|}{ \% DM retained on screen } \\
\hline Long & 8.8 & 9.1 & 0.3 & 0.7 \\
\hline Medium & 46.6 & 49.3 & 1.2 & 0.16 \\
\hline Short & 33.5 & 34.5 & 0.8 & 0.4 \\
\hline Fine & 11.0 & 7.2 & 0.8 & 0.007 \\
\hline \multicolumn{5}{|c|}{ NDF, $\%$ of screen DM } \\
\hline Long & 55.3 & 49.8 & 0.6 & 0.16 \\
\hline Medium & 32.2 & 32.2 & 0.1 & 0.99 \\
\hline Short & 22.4 & 22.1 & 0.4 & 0.7 \\
\hline Fine & 22.1 & 16.8 & 1.6 & 0.3 \\
\hline \multicolumn{5}{|c|}{ Starch, \% of screen DM } \\
\hline Long & 6.4 & 8.2 & 0.4 & 0.17 \\
\hline Medium & 27.9 & 30.0 & 0.8 & 0.3 \\
\hline Short & 31.8 & 31.8 & 0.3 & 0.9 \\
\hline Fine & 32.0 & 27.6 & 1.2 & 0.2 \\
\hline pef $^{3}$ & 55.5 & 58.3 & 1.3 & 0.16 \\
\hline peNDF, ${ }^{4} \%$ of DM & 16.4 & 17.3 & 0.4 & 0.16 \\
\hline
\end{tabular}

${ }^{1}$ Particle size was determined by a Penn State Particle Separator, which has a 19-mm screen (long), 8-mm screen (medium), 1.18-mm screen (short), and a pan (fine).

${ }^{2}$ Dry $=$ basal dry diet without water added; wet $=$ basal dry diet plus $20 \%$ water added (DM basis).

${ }^{3}$ pef $=$ physical effectiveness factor determined as the proportion of particles retained by top 2 sieves of the Penn State Particle Separator (Yang and Beauchemin, 2006).

${ }^{4}$ peNDF $=$ measured as the NDF content of the TMR (DM basis) multiplied by the pef.

sorted for these particles on the wet diet, resulting in a difference between treatments. Cows also sorted for fine particles $(<1.18 \mathrm{~mm})$ when fed the wet diet, but did not sort against these on the dry diet.

The difference in intakes between diets is reported in Table 5. Dry matter content of the feed affected DMI, which was less when cows were on the wet diet compared with the dry diet. However, the cows tended to consume more wet matter feed on the wet diet than when they were on the dry diet, which corresponded to a significantly greater intake of water in feed when fed the wet diet. Neutral detergent fiber intake was less when cows were on the wet diet, whereas the NDF concentration of diet consumed also tended to be less on this diet. Starch intake was also less when cows were on the wet diet; however, the starch concentration of the diet consumed was greater on that diet. There was no difference in percentage of feed refused of the different diets. Dietary DM had no effect on milk yield or composition (Table 6).

\section{DISCUSSION}

The 2 treatment diets in this study had the same composition but differed in DM content by $10 \%$ because of the addition of water to the TMR. The addition of water also changed the particle size distribution, reducing the amount of DM retained in the pan. This effect of water addition on feed has been previously seen with feeds of various compositions (Leonardi et al., 2005; Hosseinkhani et al., 2007) and was attributed to water causing the fine particles to stick to larger particles.

Contrary to our hypothesis, sorting was not reduced by the addition of water to the TMR; rather, the addition of water to the dry diet increased sorting. This result is in contrast to the findings of Leonardi et al. (2005) who found that adding water to a TMR reduced the degree of sorting. Surprisingly, in the present study, very little sorting of the dry diet actually occurred, with the exception of a tendency to sort against short particles. This amount and type of sorting is unusual, given that cows, both tie-stall and free-stall housed, typically have been shown to sort their TMR against long particles and for shorter particles (Leonardi and Armentano, 2003; DeVries et al., 2007; Leonardi and Armentano, 2007). In contrast to the dry diet, cows

Table 3. Dry matter percentage of particle fractions ${ }^{1}$ for fresh feed and orts from both treatment diets

\begin{tabular}{lcccc}
\hline & \multicolumn{2}{c}{ Diet $^{2}$} & & \\
\cline { 2 - 3 } Item & Dry & Wet & SE & $P$-value \\
\hline DM \% of TMR particle fractions & & & & \\
Long & 50.1 & 41.2 & 1.2 & $<0.001$ \\
Medium & 57.7 & 46.7 & 1.3 & $<0.001$ \\
Short & 60.3 & 49.6 & 1.1 & $<0.001$ \\
Fine & 59.8 & 52.2 & 0.8 & $<0.001$ \\
DM \% of orts particle fractions & & & & \\
Long & 44.4 & 36.7 & 1.6 & 0.003 \\
Medium & 50.5 & 42.0 & 1.9 & 0.003 \\
Short & 52.2 & 44.1 & 1.3 & $<0.001$ \\
Fine & 55.9 & 52.5 & 0.8 & 0.8 \\
\hline
\end{tabular}

${ }^{1}$ Particle size was determined by a Penn State Particle Separator, which has a 19-mm screen (long), 8-mm screen (medium), 1.18-mm screen (short), and a pan (fine).

${ }^{2}$ Dry = basal dry diet without water added; wet = basal dry diet plus $20 \%$ water added (DM basis). 
Table 4. Effect of dietary treatments ${ }^{1}$ on the sorting (\%) of long, medium, short, and fine particles ${ }^{2}$

\begin{tabular}{lcccc}
\hline & \multicolumn{3}{c}{ Diet } & \\
\cline { 2 - 3 } Particle size $^{3}$ & Dry & Wet & SE & P-value \\
\hline Long & 100.7 & $93.4^{*}$ & 2.7 & 0.07 \\
Medium & 100.4 & 99.4 & 0.7 & 0.3 \\
Short & $98.7 \dagger$ & $101.3^{*}$ & 0.6 & 0.001 \\
Fine & 101.2 & $104.4^{*}$ & 2.2 & 0.25 \\
\hline
\end{tabular}

${ }^{1}$ Dry $=$ control diet without water added; wet $=$ control diet plus $20 \%$ water added (DM basis).

${ }^{2}$ Sorting $\%=100 \times($ particle size $\mathrm{n} D \mathrm{DM}$ intake/particle size $\mathrm{n}$ predicted DM intake), where $\mathrm{n}=$ long, medium, short, or fine particle fraction. Sorting values equal to $100 \%$ indicate no sorting, $<100 \%$ indicate selective refusals (sorting against), and $>100 \%$ indicate preferential consumption (sorting for). Data are averaged over $3 \mathrm{~d}$ for 12 cows on each treatment.

${ }^{3}$ Particle size determined by a Penn State Particle Separator, which has a 19-mm screen (long), 8-mm screen (medium), 1.18-mm screen (short), and a pan (fine).

${ }^{*} \dagger$ Difference in sorting values from $100 \%$ expressed as $\dagger P<0.10,{ }^{*} P$ $<0.05$.

fed the wet diet sorted the TMR to a greater extent, favoring the smaller particles and refusing portions of the longer particles. The difference between the sorting of the 2 diets is not likely caused by an increased ease of sorting in the wet diet, so the addition of water clearly had some deterring effect on the consumption of long particles by the cows. The difference between these results and those of Leonardi et al. (2005) may be explained by the difference in diet composition and DM content of the diets used. Leonardi et al. (2005) used a TMR that was dryer and consisted of $30 \%$ chopped hay, whereas diets used in the present study contained no hay, utilizing haylage and corn silage as forage sources. It has been previously reported that selective refusal of long particles increases with the addition of hay to the diet (Leonardi and Armentano, 2003). The addition of water to a dry ration containing hay is likely to have a different effect on the degree of sorting of long particles than the addition of water to a wetter silage-based ration which is initially less sorted. In the present study, the long particles, primarily provided by the haylage component of the diet, were the wettest fraction of both treatment diets, having even less DM in the wet diet. As a result, these long haylage particles may have been more unpalatable in the wet diet, and easily sorted against because of their size. The short and fine particles may have been sorted for in the wet diet because these were the driest fractions of that ration.

Interestingly, cows decreased their DMI when fed the wet diet. Because milk production is positively related to DMI (Martin and Sauvant, 2002), this effect is not desirable. Although there was no difference in milk production or components between these groups, it is
Table 5. Intake of DM, nutrients, nutrient composition, and orts percentage of treatment diets ${ }^{1}$

\begin{tabular}{lrrrc}
\hline & \multicolumn{2}{c}{ Diet $^{2}$} & & \\
\cline { 2 - 3 } Item & Dry & Wet & SE & $P$-value \\
\hline DMI, kg/d & 32.8 & 29.6 & 1.4 & 0.03 \\
Wet matter intake, kg/d & 55.1 & 60.3 & 2.8 & 0.08 \\
Feed water intake, kg/d & 22.3 & 30.8 & 1.5 & $<0.001$ \\
NDF intake, kg/d & 9.7 & 8.7 & 0.4 & 0.027 \\
cNDF, $\%$ of DM & 29.5 & 29.3 & 0.1 & 0.07 \\
Starch intake, kg/d & 9.3 & 8.5 & 0.4 & 0.046 \\
cStarch, \% of DM & 28.2 & 28.6 & 0.1 & $<0.001$ \\
Orts, \% & 14.6 & 13.7 & 1.1 & 0.5 \\
\hline
\end{tabular}

${ }^{1}$ Data are averaged over $7 \mathrm{~d}$ for 12 cows on each treatment.

${ }^{2}$ Dry $=$ control diet without water added; wet $=$ control diet plus $20 \%$ water added (DM basis).

${ }^{3} \mathrm{CNDF}=\mathrm{NDF}$ concentration of diet consumed $=(\mathrm{NDF}$ intake $/ \mathrm{DMI})$ $\times 100$.

${ }^{4} \mathrm{cStarch}=$ starch concentration of diet consumed $=$ (starch intake $/$ DMI) $\times 100$.

possible that over a longer period it would have negatively affected milk production. Dry matter intake may be limited by ration DM content in a variety of ways, including differences in fermentation of silages (i.e., end product concentrations) because of DM content, increased bulk of feed caused by intracellular water, and increased intake of water (Robinson et al., 1990). In the present study, there was no difference in primary fermentation (i.e., of the silages) or intracellular water between rations because feed components were the same. Hence, the possible physical limitation on DMI in the present study would be increased intake of water. Many researchers have previously observed no effect of water addition on DMI (Thomas et al., 1961; Robinson et al., 1990; Leonardi et al., 2005). Alternatively, Lahr et al. (1983) noted a positive correlation between DMI and DM content of the diets, using diets at similar DM

Table 6. Effect of dietary DM content on milk yield, milk composition, and milk component yield

\begin{tabular}{|c|c|c|c|c|}
\hline \multirow[b]{2}{*}{ Item } & \multicolumn{2}{|c|}{$\operatorname{Diet}^{1}$} & \multirow[b]{2}{*}{$\mathrm{SE}$} & \multirow[b]{2}{*}{$P$-value } \\
\hline & Dry & Wet & & \\
\hline $\begin{array}{l}\text { Milk yield, }{ }^{2} \mathrm{~kg} / \mathrm{d} \\
\text { Milk composition, }{ }^{3} \%\end{array}$ & 37.1 & 36.3 & 1.30 & 0.3 \\
\hline Fat & 3.43 & 3.43 & 0.10 & 0.88 \\
\hline Protein & 3.44 & 3.44 & 0.06 & 0.96 \\
\hline Milk component yield, ${ }^{3} \mathrm{~kg} / \mathrm{d}$ & & & & \\
\hline Fat & 1.26 & 1.20 & 0.05 & 0.33 \\
\hline Protein & 1.26 & 1.22 & 0.04 & 0.37 \\
\hline
\end{tabular}

${ }^{1}$ Dry $=$ control diet without water added; wet $=$ control diet plus $20 \%$ water added (DM basis).

${ }^{2}$ Data are averaged over $7 \mathrm{~d}$ for 12 cows on each treatment.

${ }^{3}$ Data are averaged over $3 \mathrm{~d}$ for 12 cows on each treatment. 
content to the present study and prepared similarly by adding water directly to the TMR before feeding. In studies where water was added directly to the rumen, there was no reported decrease in DMI (Thomas et al., 1961; Estrada et al., 2003), which indicates that if intake was limited in the present study by water addition, it was likely not caused by the increased intake of water itself. We can hypothesize, rather, the possibility that the water absorbed by the feed increased its weight and bulk enough to limit intake through increased rumen fill (Allen, 1996). Results of the present study lend some support to this theory. Cows consumed slightly more feed in wet weight basis on the wet diet than on the dry diet, corresponding to an increase in feed water intake. The increased intake of wet matter was not enough to compensate for the lesser DM content of the wet diet and, therefore, the lesser DMI may have been caused by filling effect of the wet diet.

The reduced DMI in the present study and that of Lahr et al. (1983) may also be a result of a change in palatability of the feed. Robinson et al. (1990), referring to the results of Lahr et al. (1983), suggested that water has little time to be absorbed by the feed when added to the TMR during mixing and may cause the feed to be less palatable, resulting in reduced intake. Although Leonardi et al. (2005) also added water directly to the TMR, palatability of their wet diet may not have been an issue because of the greater DM contents of both treatment diets used. Palatability might then be a concern when water is added to diets, similar to the one used in the current study, that are already relatively low in DM. Such diets may also have reduced palatability caused by spoilage of the TMR in the feed bunk. Even though environmental temperature was not extreme during the present study, high-moisture TMR are less stable during periods of elevated environmental temperature (Eastridge, 2006).

Reduced DMI on the wet diet also resulted in less NDF and starch intake on that diet. Such reduction in nutrient intakes may potentially limit milk production (Chase, 1993). Interestingly, because of the sorting against the greater fiber long particles and sorting for the greater starch shorter particles on the wet diet, the actual concentration of these nutrients in the consumed diet differed between treatments. Compared with the dry diet, on the wet diet, the concentration of dietary starch consumed was greater and there was a tendency for the concentration of dietary NDF consumed to be less. Such an imbalance in ration composition consumed may increase the risk of subacute ruminal acidosis because there is less fiber intake and more starch intake than predicted (Owens et al., 1998; DeVries et al., 2008).

\section{CONCLUSIONS}

Taking into consideration the reduced DMI and increased sorting, it is possible that the addition of water to a high-moisture ration changed the palatability of the feed in a way that prompted cows to consume less and eat in a more discriminating fashion. Hence, in cases where it is typical to feed high-moisture TMR, containing primarily silage and haylage forage sources, these results do not support the addition of water as a method to discourage cows from sorting. In fact, because of reduced DMI and increased sorting of such rations, the addition of water will result in the consumption of a ration with different nutrient composition than intended.

\section{ACKNOWLEDGMENTS}

We thank the staff and students at the University of Guelph, Kemptville Campus Dairy Education and Research Centre. In particular, we thank Megan Bruce and Angela Greter of the University of Guelph, Kemptville Campus, for their technical help.

\section{REFERENCES}

Allen, M. S. 1996. Physical constraints on voluntary intake of forage by ruminants. J. Anim. Sci. 74:3063-3075.

AOAC. 2000. Official Methods of Analysis. Vol. I. 17th ed. Association of Official Analytical Chemists, Arlington, VA.

Bhandari, S. K., S. Li, K. H. Ominski, K. M. Wittenberg, and J. C. Plaizier. 2008. Effects of the chop lengths of alfalfa silage and oat silage on feed intake, milk production, feeding behavior, and rumen fermentation of dairy cows. J. Dairy Sci. 91:1942-1958.

CCAC. 1993. Guide to the Care and Use of Experimental Animals. Vol. 1. E. D. Olfert, B. M. Cross, and A. A. McWilliam, ed. Canadian Council on Animal Care, Ottawa, Canada.

Chase, L. E. 1993. Developing nutrition programs for high producing dairy herds. J. Dairy Sci. 76:3287-3293.

Coppock, C. E., D. L. Bath, and B. Harris Jr. 1981. From feeding to feeding systems. J. Dairy Sci. 64:1230-1249.

DeVries, T. J., K. A. Beauchemin, and M. A. G. von Keyserlingk. 2007. Dietary forage concentration affects the feed sorting behavior of lactating dairy cows. J. Dairy Sci. 90:5572-5579.

DeVries, T. J., F. Dohme, and K. A. Beauchemin. 2008. Repeated ruminal acidosis challenges in lactating dairy cows at high and low risk for developing acidosis: Feed sorting. J. Dairy Sci. 91:39583967.

DeVries, T. J., M. A. G. von Keyserlingk, and K. A. Beauchemin. 2005. Frequency of feed delivery affects the behavior of lactating dairy cows. J. Dairy Sci. 88:3553-3562.

Eastridge, M. L. 2006. Major advances in applied dairy cattle nutrition. J. Dairy Sci. 89:1311-1323.

Estrada, J. I. C., R. Delagarde, P. Faverdin, and J. Peyraud. 2003. The addition of external water to fresh grass does not affect dry matter intake, feeding behaviour and rumen characteristics in dairy cows. Anim. Res. 52:3-16.

Hosseinkhani, A., R. Valizadeh, A. Naserian, M. D. Mesgharan, and F. E. Shahroodi. 2007. Effect of alfalfa hay particle size and water addition to barley base diets on dairy cows performance in early lactation. J. Anim. Vet. Adv. 6:1482-1488.

Kononoff, P. J., A. J. Heinrichs, and D. R. Buckmaster. 2003. Modification of Penn State forage and total mixed ration particle 
separator and the effects of moisture content on its measurements. J. Dairy Sci. 86:1858-1863.

Lahr, D. A., D. E. Otterby, D. G. Johnson, J. G. Linn, and R. G. Lundquist. 1983. Effects of moisture content of complete diets on feed intake and milk production in dairy cows. J. Dairy Sci. 66:1891-1900.

Leonardi, C., and L. E. Armentano. 2003. Effect of quantity, quality, and length of alfalfa hay on selective consumption by dairy cows. J. Dairy Sci. 86:557-564.

Leonardi, C., and L. E. Armentano. 2007. Feed selection by dairy cows fed individually in a tie-stall or as a group in a free-stall barn. J. Dairy Sci. 90:2386-2389.

Leonardi, C., F. Giannico, and L. E. Armentano. 2005. Effect of water addition on selective consumption (sorting) of dry diets by dairy cattle. J. Dairy Sci. 88:1043-1049.

Martin, O., and D. Sauvant. 2002. Metaanalysis of input/output kinetics in lactating dairy cows. J. Dairy Sci. 85:3363-3381.

Morris, T. R. 1999. Experimental Design and Analysis in Animal Sciences. CABI Publishing, New York, NY.
National Research Council. 2001. Nutrient Requirements for Dairy Cattle. Natl. Acad. Sci. Washington, DC.

Owens, F. N., D. S. Secrist, W. J. Hill, and D. R. Gill. 1998. Acidosis in cattle: A review. J. Anim. Sci. 76:275-286.

Robinson, P. H., P. L. Burgess, and R. E. McQueen. 1990. Influence of moisture content of mixed rations on feed intake and milk production of dairy cows. J. Dairy Sci. 73:2916-2921.

SAS Institute. 2003. SAS Users Guide. SAS Inst. Inc., Cary, NC.

Shaver, R. D. 2002. Rumen acidosis in dairy cattle: Bunk management considerations. Adv. Dairy Technol. 14:241-249.

Thomas, J. W., L. A. Moore, M. Okamoto, and J. F. Sykes. 1961. A study of factors affecting rate of intake of heifers fed silage. J. Dairy Sci. 44:1471-1483.

Van Soest, P. J., J. B. Robertson, and B. A. Lewis. 1991. Methods for dietary fiber, neutral detergent fiber and non-starch polysaccharide in relation to animal nutrition. J. Dairy Sci. 74:3583-3597.

Yang, W. Z., and K. A. Beauchemin. 2006. Physically effective fiber: Method of determination and effects on chewing, ruminal acidosis, and digestion by dairy cows. J. Dairy Sci. 89:2618-2633. 